\title{
A IMPORTÂNCIA DA CONSULTA DE ENFERMAGEM NA PRÁTICA AMBULATORIAL E O SEU IMPACTO FRENTE AO PREPARO PARA REALIZAÇÃO DA COLONOSCOPIA
}

\author{
Eixo temático: Avaliação e Qualidade do Cuidado
}

\section{INTRODUÇÃO}

A colonoscopia é um exame que permite a visualização completa da mucosa do colón e íleo terminal. É considerado um método diagnóstico e de tratamento de doenças colorretais. Para sua realização é necessário preparo do cólon com laxantes e dieta líquida, de acordo com a prescrição médica ou protocolo institucional.' A Consulta de Enfermagem é atividade privativa do enfermeiro, esta denominação foi criada em 1968 no Rio De Janeiro e é considerada a atividade final de maior importância, onde se utiliza o processo de enfermagem como método para sistematizar a assistência e estimular que os enfermeiros usem o raciocínio clínico e o pensamento crítico no cuidado e no planejamento da assistência, dando maior eficiência, objetividade, segurança e qualidade ao seu trabalho².

\section{OBJETIVO}

Evidenciar a importância da consulta de enfermagem e seu impacto na realização do exame e segurança do diagnóstico, do paciente submetido à Colonoscopia em âmbito Ambulatorial no Hospital Municipal Dr. José De Carvalho Florence.

\section{METODOLOGIA}

Análise retrospectiva quantitativa de um banco de dados, de Janeiro á Junho de 2018, foram analisados laudos médicos das colonoscopias com ênfase no preparo.

\section{RESULTADO}

Foram analisados 443 laudos médicos de pacientes submetidos ao exame de colonoscopia. Destes, 387 realizaram a consulta de enfermagem antes da realização do exame, onde se realiza também a orientação para o preparo do cólon, 73,7\% obtiveram êxito no preparo, e 26,3 \% estavam com preparo inadequado. 56 laudos eram de pacientes que não passaram pela consulta de enfermagem e foi observado que somente $21,4 \%$ obtiveram êxito no preparo, $69,6 \%$ estavam com preparo inadequado e $9 \%$ tiveram 0 exame suspenso por falta de preparo.

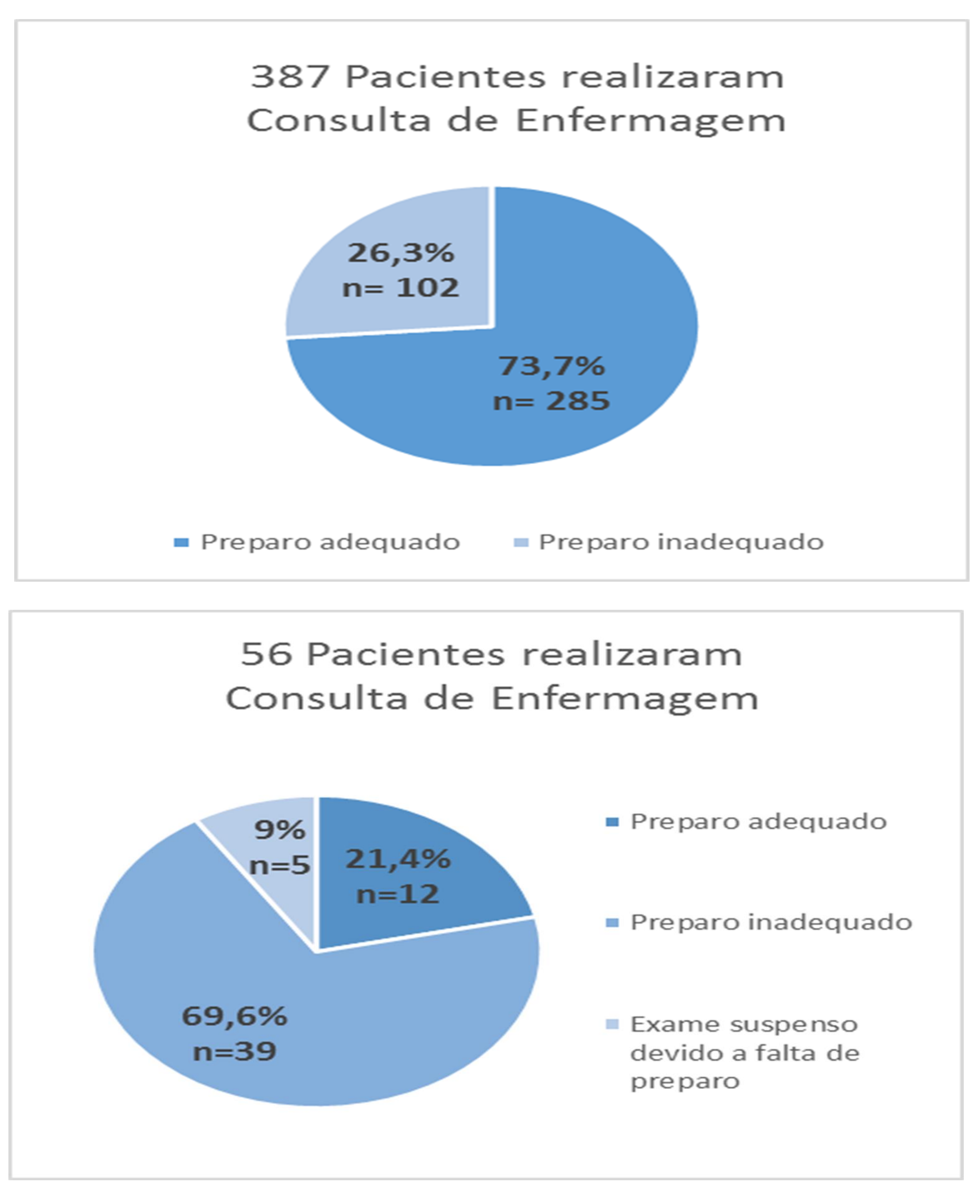

\section{CONCLUSÃO}

A realização da Consulta de Enfermagem é necessária como processo de educação e orientação em saúde, auxiliando diretamente o paciente no preparo para realização da colonoscopia e quando não realizada tem impacto negativo na eficácia do exame e na segurança do diagnóstico.

REFERÊNCIAS: (1) DANI, R.; CASTRO, D. L.. Gastroenterologia Clínica: 3. ed. Rio De Janeiro: Guanabara Koogan S.A., 1993.(2) OLIVEIRA, Sherida Karanini Paz de et al. Temas abordados na consulta de enfermagem: revisão integrativa da literatura. Rev. bras. enferm., Brasília, v. 65, n. 1, p. 155-161, Fev. 2012. 